\title{
"DEPENDÊNCIA" DO EMPREGADOR E "LEALDADE" DO TRABALHADOR NA FÁBRICA DO FUTURO: evidência com base no Brasil ${ }^{*}$
}

\section{Lee Pegler}

\section{Introdução}

No início da década de 1990, um grande número de especialistas sugere que os empregadores que modernizarem seus sistemas de gestão e do local de trabalho possivelmente vão se tornar mais dependentes da qualificação e das atitudes de seus empregados. ${ }^{1}$ Todavia, a freqüente observação do desenvolvimento de mecanismos de controle do trabalho mais sofisticados põe em dúvida a dedução de que o trabalho e as atitudes em relação a ele, em grande medida, "vão melhorar" na empresa modernizada. ${ }^{2}$ No entanto, outros autores vão além de uma crença nos efeitos que mudanças relativas ao trabalho possam ter, por si só, sobre as atitudes. Sugerem que os trabalhadores

* Research Fellow, Centre for Research into Economic and Social Transformation (CREST), School of Social Sciences, Cardiff University.

Tradução de Wanda Caldeira Brant das empresas modernizadas serão persuadidos a fazer "mais do que o estabelecido em contrato", devido ao surgimento de uma forma de vínculo forte e direto com o empregador. ${ }^{3}$ Além disso, não se sabe que conseqüência o desaparecimento das atitudes "nós e eles" poderá ter sobre as atitudes do trabalhador em relação a seu sindicato.

O objetivo deste artigo é estudar esses debates sobre a dependência do empregador e as atitudes do trabalhador em relação ao empregador e ao sindicato. O empregador torna-se realmente mais aberto e democrático e o "eixo de lealdade" mudou como os otimistas sugerem? Mais especificamente, em que medida os trabalhadores estão mais ligados a seu empregador? Isso indica também que o sindicato poderá se tornar cada vez mais irrelevante para os trabalhadores no âmbito dessa nova empresa de "ganhos mútuos"?

O contexto em que o estudo que serve de base para este artigo foi realizado é a indústria brasileira de refrigeradores e máquinas de lavar duran- 
te a década de 1990 (Pegler, 2000). Nesse estudo, o teste de hipóteses sobre mudanças relativas ao trabalho e de atitudes em relação ao empregador e ao sindicato baseou-se em uma comparação entre as respostas dos trabalhadores de empresas que mudaram pouco e de empresas que se modernizaram de maneira mais abrangente. Os dados foram obtidos por meio de entrevistas intensivas com aproximadamente cem trabalhadores de quatro companhias de eletrodomésticos de grande porte.

Este artigo encontra-se estruturado em seis seções. Na seção 2 são definidos os conceitos em questão e sintetizados os argumentos de um número proeminente de autores americanos e ingleses que trabalham nessas áreas de pesquisa. A seção 3 oferece uma visão geral de como essas questões da dependência do empregador e da lealdade do trabalhador são vistas no contexto brasileiro. Por outro lado, a seção 4 sintetiza a natureza da política e da prática de modernização no caso das empresas estudadas, principalmente daquelas que se modernizaram de maneira mais abrangente. As ambigüidades que essa análise deixa, no que diz respeito à política do empregador e às mudanças relativas ao trabalho, indicam que o argumento otimista da modernização deve estar baseado nas mudanças de atitudes em relação ao empregador e ao sindicato. Por isso a seção 5 apresenta evidências elementares sobre as possíveis mudanças de atitudes do trabalhador em relação ao empregador e ao sindicato como resultado do processo de modernização e também a maneira como se deram essas mudanças. Na subseção 5.1 são analisadas as respostas dos trabalhadores a questões como, por exemplo, quando o empregador tem mais lucro, o que ganham ou poderiam ganhar; qual a probabilidade que têm de deixar a empresa etc. Por outro lado, a subseção 5.2 revela como os trabalhadores avaliam seu sindicato e com o que querem que ele se envolva. A seção 6 sintetiza o artigo e apresenta as conclusões.

\section{Considerações teóricas e empíricas}

De acordo com os otimistas, a "fábrica do futuro" é símbolo de uma modernização substancial da estratégia e das estruturas de gestão, assim como de mudanças significativas em relação ao chão de fábrica. ${ }^{4}$ Segundo esses autores, no nível da gestão da empresa, isso implica a promoção de qualidade e a melhora contínua por meio de uma determinação de novas tarefas, de estruturas organizacionais mais simples e de políticas de recursos humanos mais generosas e democráticas, além de sistemas de incentivos. No chão de fábrica, a modernização envolve novas tecnologias e técnicas de produção e um novo modelo de trabalho. Diante dessa perspectiva, os otimistas argumentam que o trabalho será baseado em níveis mais altos de responsabilidade e de autonomia e em melhores condições de emprego (por exemplo, maior treinamento) e das relações de trabalho (por exemplo, novas formas de envolvimento). ${ }^{5}$

Esse esquema tem como base a idéia aparentemente simples de que a modernização levará a uma mudança de atitudes que, por sua vez, possibilitará a melhoria do desempenho da companhia. Existem três importantes relações causais contidas nessa idéia. ${ }^{6}$ A primeira é que as políticas de modernização modificam a natureza do trabalho e as atitudes em relação a ele. A segunda é que essas políticas vão alterar o grau de ligação do trabalhador com a empresa (e com o sindicato). A terceira é que, devido a essas mudanças de atitudes, os sindicatos deverão alterar sua abordagem para continuarem a ser órgãos representativos e efetivos. Para os otimistas, o conceito de "nós e eles" não é mais relevante. As empresas vão se tornar mais dependentes das atitudes e da qualificação dos trabalhadores que, por sua vez, vão demonstrar maior lealdade à empresa, e os sindicatos terão que modificar seu comportamento (ou seja, deverão se tornar mais moderados), de modo que não se tornem "eles" aos olhos dos trabalhadores. ${ }^{7}$

Este artigo enfoca a segunda dessas relações, pois estudos anteriores enfocavam a relação entre mudanças relativas ao trabalho, mudanças de atitude em relação a ele e desempenho das empresas (ou seja, a primeira relação), mas uma literatura mais recente passou a questionar seriamente essa hipótese. Há indícios de que a referida literatura levantou uma questão significativa: a de saber se a satisfação no emprego atinge gradualmente o 
desempenho da empresa e se, de fato, os trabalhadores realmente gostam de suas novas tarefas, mesmo no Japão. ${ }^{8}$ Portanto, os otimistas mais recentes enfocam com mais clareza as atitudes em relação ao empregador (e ao sindicato) como resultado das políticas de modernização.

Conseqüentemente, o que a literatura internacional sugere sobre o novo empregador, mais aberto e dependente? Além disso, houve uma mudança no "eixo de lealdade do trabalhador" para com o empregador e um distanciamento do sindicato? No primeiro caso, o debate sobre se os empregadores tornaram-se mais dependentes dos trabalhadores como resultado da modernização pode ser dividido em duas escolas de pensamento - a dos otimistas e a dos pessimistas.

Um grande número de otimistas, que concentra sua atenção nos efeitos da modernização sobre as atitudes em relação ao empregador, faz uso de amplos e integrados modelos de mudança da empresa. Conceitos como a "empresa de ganhos mútuos" (Kochan e Osterman, 1994), "produção americana em equipe"(Appelbaum e Batt, 1994) e "corporativismo do bem-estar" (Lincoln e Kallenberg, 1989) foram sugeridos. Cada um desses conceitos baseia-se na utilização, por parte da empresa, de uma série de políticas estratégicas - de recursos humanos e de locais de trabalho - integradas (ver Kochan e Osterman, 1994, cap. 3). Além disso, esses autores estabelecem ou assumem que uma forma abrangente de modernização está emergindo.

Todavia, as pesquisas desses autores não apresentam evidências muito convincentes. Assim, exemplos de empresas que modificaram suas políticas estratégicas de recursos humanos e de locais de trabalho continuam raros. (Kochan e Osterman, 1994, p. 79-109; Appelbaum e Batt, 1994, p. 69-97) ${ }^{9}$ A evidência do estudo de caso usado para fundamentar a "empresa de ganhos mútuos" e a "produção americana em equipe" também não é muito convincente (idem, pp. 58-77; idem). ${ }^{10} \mathrm{O}$ uso de exemplos dos "melhores casos" (por exemplo, Saturn, CAMMI, Xerox e Nissan) simplesmente evidencia sua condição de minoria e de setor-chave. A maior parte dos outros estudos de caso examinados demonstra que, apesar da re- tórica, os empregadores estão preparados apenas para fazer pequenas modificações no envolvimento, na participação e na distribuição dos lucros. Novas formas de treinamento são, com freqüência, altamente voltadas para funções específicas da empresa em questão ou para atitudes relativas à mesma.

Outros autores são mais pessimistas. Para eles, a maior parte dos exemplos de modernização é parcial, devido à interação entre o contexto e a falta de realismo inerente ao argumento otimista. Ao contrário, onde surgem exemplos abrangentes, qualquer tendência a uma maior dependência do empregador em relação à qualificação e às atitudes do trabalhador será contrabalançada por novas e mais onerosas formas de controle do que as que eram evidentes nas formas anteriores do regime de fábrica. Por exemplo, por meio de uma observação participante detalhada, Graham observa que o que se desenvolveu dentro da fábrica altamente modernizada foi, na verdade, um sistema mais completo de controle (1994, pp. 123-151). Os mecanismos por meio dos quais desenvolve suas observações do monitoramento intensificado, da pressão e de uma menor autonomia incluem: o processo de seleção, orientação e treinamento, as pressões de grupo, o JIT (just-in-time) técnico e os sistemas de linha utilizados (idem, pp. 132-141).

Autores como Garrahan e Stewart (1992, pp. 46-62), Rinehart et al. (1994, pp. 152-174), Delbridge (1995, pp. 803-817) e Taylor et al. (1994, pp. 196-225) sustentam esse ponto de vista. Onde a perspectiva de uma maior dependência do empregador cresce, os empregadores respondem, freqüentemente, com formas de controle mais sofisticadas e mais onerosas. ${ }^{11}$ Além disso, fatores históricos, locais e contextuais mais amplos desempenham um papel crucial no tipo e no grau de modernização, assim como no surgimento dos sistemas de controle.

Portanto, se novos sistemas de fábrica podem ser caracterizados como mais controladores, o que isso sugere a respeito das atitudes dos trabalhadores em relação ao empregador e ao sindicato? Em seguida, se os trabalhadores estão sujeitos a um controle maior, que oportunidades de re- 
sistência têm agora? Sobre essas questões, a literatura pode ser dividida também em um grupo de otimistas e outro de pessimistas.

Como sugerido anteriormente, os otimistas acreditam que haverá um grau maior de ligação (envolvimento) com a empresa. Um dos argumentos mais convincentes sobre isso encontra-se na análise comparativa de empresas americanas e japonesas feita por Lincoln e por Kallenberg (1989, cap. 9). Além disso, é importante observar que muitos desses autores otimistas também argumentam que a sobrevivência a longo prazo de uma estratégia de modernização abrangente requer o papel ativo de sindicatos. Todavia, isso implica que os sindicatos devem dar mais apoio à empresa do que freqüentemente acontece (ver, por exemplo, idem, pp. 229-232). Isso também inclui a suposição implícita de que os trabalhadores podem manter uma dupla lealdade - à empresa e ao sindicato.

Em um contraste bem definido, os pessimistas, como Graham, apontam a pressão das políticas das empresas sobre as atitudes e o comportamento dos trabalhadores (Graham, 1994, pp. 141-147). Muitos deles não acreditam na "nova" mensagem das empresas, mas são freqüentemente obrigados, pela transparência do sistema de fábrica, a expressar abertamente o que pensam. Reinhart et al e outros autores observam também que alguns trabalhadores acreditam na nova empresa, alguns arriscam abertamente um comportamento cínico enquanto outros agem como se apoiassem a empresa e suas políticas (1994, pp. 164-165).

Os sistemas de fábrica transparentes, combinados com a mensagem unitária da "nova" empresa, significam que as formas de resistência tradicionais (tanto dentro quanto fora da fábrica) tornamse mais difíceis de serem sustentadas (Delbridge, 1995, pp. 812-814). Nesse tipo de situação, sindicatos combativos comentam as novas dificuldades que encontram em suas tentativas de agirem como uma "voz" dos trabalhadores (Reinhart et al., 1994, pp. 166-169). Esse cenário também dificulta imaginar que os trabalhadores poderiam ter lealdade, tanto com o sindicato quanto com a empresa, uma questão tratada pela literatura anterior sobre dupla lealdade (ver, por exemplo, Guest, 1995, pp. 112117; Lincoln e Kallenberg, 1989, pp. 23-24).
Neste sentido, formas mais sutis de políticas de controle do local de trabalho podem simplesmente agravar os problemas estruturais e de representação enfrentados pelos sindicatos. ${ }^{12}$ Por exemplo, os trabalhadores podem gostar de alguns aspectos dos novos sistemas fabris (tais como o treinamento, os esquemas de carreira etc.) ou devem agir "como se" gostassem. Isso significa que a perspectiva de que eles vão apoiar os sindicatos torna-se realmente mais incerta. Se os sindicatos devem, então, adotar identidades moderadas ou militantes torna-se, assim, uma questão mais complexa - especialmente em contextos em que já enfrentam um ambiente difícil. ${ }^{13}$

Em síntese, essa breve visão geral do debate internacional sobre a dependência do empregador e a lealdade do trabalhador sugere uma série de pontos relativos à análise dessas questões no Brasil. Em primeiro lugar, há evidências significativas para sugerir que, mesmo quando os empregadores iniciam uma estratégia de modernização abrangente, reagirão à perspectiva de sua maior dependência dos trabalhadores com novas e mais sutis formas de controle. Em segundo lugar, nesse contexto, os trabalhadores podem tomar uma série de atitudes e demonstrar várias respostas comportamentais. Isso torna mais clara a inter-relação contínua entre consentimento, controle, conflito e resistência dentro da "fábrica do futuro". Finalmente, a forma de modernização assim como a natureza da dependência do empregador e da lealdade do trabalhador podem variar significativamente de acordo com o contexto. Conseqüentemente, com o objetivo de uma preparação para a análise das empresas dos estudos de caso na seção 4, a próxima seção discute o contexto em torno do qual se dá a modernização recente no Brasil.

\section{Dependência do empregador e lealdade do trabalhador no contexto brasileiro}

A década de 1990 assistiu a um crescimento significativo de interesse nos possíveis efeitos das políticas de modernização sobre a competitividade industrial e o desenvolvimento econômico no Brasil. Qualidade e produtividade tornaram-se 
slogans dominantes da indústria e do governo. ${ }^{14}$ Especialistas acadêmicos também tornaram-se mais confiantes em relação aos benefícios potenciais para o trabalho e para os trabalhadores. Todavia, isso representa uma grande mudança do modelo de relações industriais do passado. Esse modelo, em grande medida excludente e corporativista, e seu lugar em um sistema político autoritário denotavam que poucas mudanças, como aquelas sugeridas pelos otimistas da modernização, poderiam ser previstas. ${ }^{15}$

O modelo de desenvolvimento baseado no Estado, muito cercado por uma série de regras, que governa o comportamento do sindicato e do trabalhador, iniciado na década de 1930, mudou pouco até meados da década de $1980 .{ }^{16}$ Ao mesmo tempo que foi aplicado em diferentes graus pelos regimes subseqüentes, o modelo de relações industriais continuou baseado em três "pilares": o papel regulatório do ministro do Trabalho, a legislação trabalhista e os sistemas relacionados do bem-estar social e do Tribunal do Trabalho.

Uma das conseqüências dessas legislações e desses órgãos era determinar, prever e reforçar um modelo de sindicalismo que tornava os sindicatos, estabelecidos fora do local de trabalho, administradores do bem-estar social. Várias regulações, que governavam as estruturas e finanças sindicais, e os poderes normativos dos tribunais do trabalho restringirem as greves demonstravam que o sindicalismo era altamente controlado em todos os níveis. No que se refere à determinação de suas condições, ao mesmo tempo que muitos benefícios estatutários básicos foram estabelecidos, os trabalhadores foram, em grande medida, deixados aos caprichos de uma classe de empregadores muito paternalista e autoritária. ${ }^{17}$

Coações econômicas e pressões sociais e políticas, iniciadas no final da década de 1970, levaram a um lento processo de democratização após 1985 (ver Keck, 1989). Enquanto a economia e a política econômica oscilaram de maneira considerável durante a década de 1980, em 1989 muitas das coações à ação dos sindicatos e dos trabalhadores também foram relaxadas. ${ }^{18}$ No entanto, o monopólio de representação dos sindicatos locais foi mantido, assim, como um sistema de financia- mento automático do sindicato. Além disso, os direitos de representação no local de trabalho (e outras questões importantes para o movimento do "novo sindicato") permanecem incertos e dependentes da negociação local. Isto significa que os sindicatos ainda podem sobreviver sem ter de ser ativos e representativos, particularmente no nível do local de trabalho.

Até o final da década de 1970, a maior parte dos estudos sobre fábricas brasileiras ${ }^{19}$ constata um salário muito baixo e uma alta rotatividade entre os locais de trabalho. Neles, havia poucas questões de dependência do empregador. Todavia, estudos sobre atitudes dos trabalhadores indicaram que muitos deles tinham mais confiança em um Estado forte do que em objetivos políticos amplos e, de certa maneira, distantes como os de muitos dos movimentos sindicais anteriores ao final daquela década. ${ }^{20}$

Ao contrário, entre a década de 1980 e o final da de 1990 houve sinais de que a situação estava mudando. Em primeiro lugar, até meados da década de 1980, muitos estudos de fábricas caracterizavam as condições fabris como "rotinizadas". ${ }^{21}$ Este termo abrangia a prerrogativa empresarial relativamente irrestrita de impor tarefas especificamente fragmentadas, substituição do trabalho extensivo, baixos salários e alta rotatividade. Um importante estudo sobre as atitudes dos trabalhadores naquela época confirmou que, ao mesmo tempo que ficavam freqüentemente fascinados pelas novas tecnologias, tinham medo de serem substituídos, assim como de uma impotência, de condições de trabalho mais onerosas e de um abuso do empregador de modo geral (Abramo, 1988). Ao mesmo tempo que a situação nas empresas em que os sindicatos eram mais influentes modificava essas experiências e opiniões, havia suspeitas amplamente sustentadas de que as empresas tinham ganhos de produtividade à custa dos trabalhadores e de que sua autonomia era cada vez mais sacrificada.

Todavia, ao longo da progressiva liberalização dos processos de relações políticas e industriais durante o final da década de 1980, estudos sobre as fábricas começaram a observar um modelo de modernização mais desenvolvido. A expressão just-in- 
time taylorizado chegou a ser usada (por alguns) para descrever uma fábrica parcialmente modernizada em que aos trabalhadores eram dadas novas tarefas, mas dentro da qual eles continuavam a trabalhar sob condições altamente monitorizadas e sob pressão. ${ }^{22}$ M. Leite (1994a), em um importante estudo das atitudes dos trabalhadores durante esse período, confirmou assim muitas das conclusões pessimistas, relativas às condições e às atitudes dos trabalhadores, da pesquisa de Abramo (1988). Nele é também indicado o possível uso crescente de greenfields" por empregadores que modernizaram suas fábricas, assim como a maior confiança que um sindicato ativo deu aos trabalhadores.

Apesar da instabilidade criada pela maior abertura da economia brasileira, no início da década de 1990, havia nítidos sinais de que um maior número de empresas estava começando a aplicar modelos de modernização mais abrangentes (ver Fleury e Humphrey, 1993; Humphrey, 1994; Gonçalves e Dreyfus, 1995). Embora de modo geral apenas nas grandes empresas domésticas e subsidiárias das companhias transnacionais, os próprios empregadores pareciam abertos a uma perspectiva de maior dependência da qualificação e das atitudes de seus empregados. Os trabalhadores passaram a ter mais envolvimento, os trabalhos tornaram-se mais diversificados, treinamento e outras novas condições foram oferecidos, e hierarquias e níveis de supervisão foram reduzidos. Melhorias significativas de qualidade, produtividade, níveis de resíduos e absenteísmo também começaram a ser registrados com mais freqüência (ver Dieese, 1995).

No entanto, são poucos os estudos dessa fase mais recente da modernização brasileira que utilizam entrevistas detalhadas com os trabalhadores - especialmente sobre o que pensam de seus empregadores e sindicatos. Além disso, há indícios (devido ao uso de sistemas de seleção e de avaliação mais restritivos) de que os modernizadores brasileiros estão também reagindo à ameaça de sua maior dependência por intermédio de novos sistemas de controle (Humphrey, 1995, p. 789). O fato de se utilizar greenfields e de os sindicatos ainda não estarem envolvidos parece dar suporte a essa idéia.
Devido a esse contexto particular, Fleury e Humphey (1993, pp. 36-42) sugeriram que o estágio recente da modernização brasileira pode ser caracterizado como uma "negociação implícita" uma nova negociação sobre as condições dos locais de trabalho (em troca de maior qualidade/produtividade) está sendo feita. Todavia, devido às tradições das relações industriais anteriores, não se trata de uma troca explícita. Neste sentido, outros sugerem que a maior parte dos empregadores optará pelo caminho da modernização "mais fácil" (mais limitada e controlada) possível (ver Castro, 1993; Leite, 1994b). Conseqüentemente, o melhor que se pode esperar em relação às atitudes dos trabalhadores é uma aprovação.

Por outro lado, o sindicalismo fraco e a reputada passividade dos trabalhadores brasileiros sugerem que, mesmo uma estratégia de modernização "fácil", poderia levar à obtenção dos níveis de lealdade dos trabalhadores requerido pelos empregadores para alcançarem os níveis de produtividade e de qualidade que desejam. Todavia, a determinação da relação (mais recente) entre um modelo de modernização do empregador e a natureza da lealdade do trabalhador requer um grande número de informações sobre as atitudes dos trabalhadores, que raramente é fornecido. Sem essas informações, os otimistas podem sugerir que os trabalhadores têm lealdade enquanto os pessimistas podem alegar que a "falsa consciência" tem um nova forma - os trabalhadores são, agora, enganados pelas políticas de "qualidade" da empresa modernizada.

As próximas seções deste artigo utilizam dados inéditos sobre essas questões. A seção 5 mostra como os trabalhadores de uma amostra extraída de quatro empresas brasileiras comparáveis se sentem em relação ao empregador modernizado e a seu sindicato. A seção 4 monta o cenário para isso, por meio de uma breve análise da natureza da modernização no caso das empresas estudadas. Um aspecto importante dessa análise diz respeito a como as empresas altamente modernizadas reagiram ao risco de se tornarem mais dependentes da qualificação e das atitudes de seus empregados. 


\section{Quadro 1}

Características Gerais das Empresas dos Estudos de Caso

\begin{tabular}{|c|c|c|c|}
\hline Empresa/(local) & Tipo de localização & $\begin{array}{l}\text { Vínculos com a } \\
\text { transnacional (TNC) }\end{array}$ & Estrutura econômica local \\
\hline $\begin{array}{l}\text { MAIS MODERNIZADAS: } \\
\text { Brastemp } \\
\text { (Rio Claro) }\end{array}$ & Greenfield & Fortes/diretos & $\begin{array}{l}\text { Muito poucas indústrias/ } \\
\text { Algumas manufaturas } \\
\text { tradicionais }\end{array}$ \\
\hline $\begin{array}{l}\text { Consul III } \\
\text { (Joinville) }\end{array}$ & $\begin{array}{l}\text { Brownfield } \\
\text { mas dividida }\end{array}$ & & $\begin{array}{l}\text { Áreas de manufaturas } \\
\text { moderadamente importantes }\end{array}$ \\
\hline $\begin{array}{l}\text { MENOS MODERNIZADAS: } \\
\text { Enxuta } \\
\text { (Caxias) }\end{array}$ & $\begin{array}{l}\text { Nova localização } \\
\text { em antiga área }\end{array}$ & Nenhum & $\begin{array}{l}\text { Base industrial importante } \\
\text { regionalmente }\end{array}$ \\
\hline $\begin{array}{l}\text { Brastemp } \\
\text { (São Bernardo) }\end{array}$ & Brownfield & Fortes/diretos & $\begin{array}{l}\text { Base industrial concentrada } \\
\text { muito importante }\end{array}$ \\
\hline $\begin{array}{l}\text { Consul II } \\
\text { (Joinville) }\end{array}$ & Brownfield & Fortes/diretos & $\begin{array}{l}\text { Base manufatureira } \\
\text { moderadamente importante }\end{array}$ \\
\hline
\end{tabular}

* Áreas sem tradição sindical. (N.T.)

Fonte: Observação, entrevistas e dados secundários.

\section{Modernização nas empresas dos estudos de caso - política e prática}

Quatro empresas da indústria de refrigeradores e máquinas de lavar, não estudadas anteriormente, foram escolhidas para estudos de caso. Duas dessas empresas (três fábricas) produzem refrigeradores e as outras duas lavadoras (ou melhor, máquinas de lavar roupa e louça e secadoras de roupa). Embora haja importantes semelhanças entre todas as empresas, o agrupamento de duas em duas funcionou particularmente bem. Cada agrupamento de dimensão comparável tinha potencialmente as mesmas exigências de produção, e uma empresa de cada grupo parecia estar muito avançada em seu processo de modernização enquanto as outras podiam ser chamadas de tradicionais ou parcialmente modernizadas. As características gerais dessas empresas dos estudos de caso são apresentadas no Quadro 1.

Como mostra o Quadro 1, os estudos de caso demonstraram diferenças relativas ao tipo de localização, aos vínculos com a TNC (Whirlpool) e à estrutura econômica local. Essas características fornecem um certo suporte para a suposição pessimista de que as fábricas que se modernizarem vão se localizar em áreas greenfields e terão vínculos mais fortes com as transnacionais do que outras empresas. A análise detalhada por meio de um estudo mais amplo da política e prática de modernização ilustra que, na verdade, essas características são importantes na tentativa de encontrar uma forma estratégica de modernização. ${ }^{23}$

Por outro lado, os quadros 2 e 3 fornecem um resumo das diferenças fundamentais entre essas empresas. Ilustram as grandes diferenças existentes nos processos e produtos das altamente modernizadas Brastemp-Rio Claro (Quadro 3, lavadoras) e das fábricas da Consul III (Quadro 2, refrigeradores) comparadas às situações em outros estabelecimentos. Além disso, a discussão subseqüente salienta como esses dois exemplos parecem dar suporte a muitas características do modelo otimista de modernização. ${ }^{24}$ 
Quadro 2

Tipologias das Fábricas e Resultados - Refrigeradores

\begin{tabular}{|c|c|c|c|}
\hline Indicador/Fábrica & $\begin{array}{l}\text { Brastemp } \\
\text { São Bernardo }\end{array}$ & Consul II & Consul III \\
\hline $\begin{array}{l}\text { Estilo e estruturas } \\
\text { de gestão }\end{array}$ & $\begin{array}{l}\text { Relativamente hierárquico } \\
\text { e fechado }\end{array}$ & $\begin{array}{l}\text { Uma certa redução nas } \\
\text { hierarquias; mais participativo }\end{array}$ & $\begin{array}{l}\text { Estruturas planas, relações } \\
\text { abertas, totalmente } \\
\text { participativo }\end{array}$ \\
\hline $\begin{array}{l}\text { Tecnologia, técnicas } \\
\text { e layout }\end{array}$ & $\begin{array}{l}\text { Mais antigas e não- } \\
\text { integradas }\end{array}$ & Mistas/não-integradas & Novas e integradas \\
\hline $\begin{array}{l}\text { Local de trabalho e } \\
\text { políticas de recursos } \\
\text { humanos }\end{array}$ & $\begin{array}{l}\text { Relação com base } \\
\text { principalmente no salário/ } \\
\text { mudanças recentes }\end{array}$ & $\begin{array}{l}\text { Algumas tarefas novas/ } \\
\text { treinamento }\end{array}$ & $\begin{array}{l}\text { Tarefas novas, treinamento } \\
\text { e ambiente do local } \\
\text { de trabalho }\end{array}$ \\
\hline Supervisão & Antiga/aberta & Estilo mais novo & Nova e aberta \\
\hline $\begin{array}{l}\text { RESULTADOS: } \\
\text { Produtividade = } \\
\text { produtos diários por } \\
\text { trabalhador }\end{array}$ & 1,7 & 1,2 & 2,6 \\
\hline Rotatividade $=\%$ anual & $8,4 \%$ & $6,0 \%$ & $1,5 \%$ \\
\hline $\begin{array}{l}\text { Salários = US \$ mensais; } \\
\text { Qualificação de peso }\end{array}$ & US \$ 430 & US \$ 344 & US \$ 365 \\
\hline $\begin{array}{l}\text { Supervisão }=\% \text { de } \\
\text { empregos da fábrica }\end{array}$ & $6,3 \%$ & $2,1 \%$ & $1,4 \%$ \\
\hline $\begin{array}{l}\text { Nível de Qualificação: } \\
\text { - \% de qualificados } \\
\text { - \% de semi-qualificados } \\
\text { - \% de não-qualificados }\end{array}$ & $\begin{array}{l}13 \% \\
12 \% \\
75 \%\end{array}$ & $\begin{array}{l}9 \% \\
11 \% \\
80 \%\end{array}$ & $\begin{array}{l}10 \% \\
30 \% \\
60 \%\end{array}$ \\
\hline
\end{tabular}

Por exemplo, em termos do estilo e das estruturas de gestão (Quadros 2 e 3, linha 1), essas duas empresas (Brastemp-Rio Claro/Consul III) e suas matrizes (Multibrás/Whirlpool) desenvolveram um plano e uma estratégia de gestão que refletem a qualidade, o aperfeiçoamento contínuo e os princípios de recursos humanos do TQM (Total Quality Model) e do HRM (Human Resources Model) em um sentido clássico. Essa estratégia foi praticamente aprofundada em todas as empresas, provocando significativas reduções nas hierarquias relatadas, assim como incentivando novos mecanismos participativos, equipes de trabalho e oportunidades de treinamento. Essas mudanças foram acompanhadas de integração de novas tecnologias de processo, técnicas como JIT/kanban e procedimentos de manutenção/qualidade.
A natureza da qualificação, as relações e as condições de trabalho também contrastam de maneira marcante com as tentativas de mudanças graduais nas outras empresas (Quadros 2 e 3, linha 3). Por exemplo, embora todos os níveis de qualificação sugiram efeitos ambíguos (Quadros 2 e 3, linha 10) devido à modernização, isto acontece principalmente em virtude das relações estruturais entre as empresas Multibrás/Whirlpool. Na verdade, a observação confirmou que os trabalhadores das duas empresas altamente modernizadas têm um grande número de novas tarefas e responsabilidades.

Em termos das relações de trabalho, os trabalhadores das duas empresas altamente modernizadas têm relações de grupo mais próximas, supervisão aberta reduzida e inúmeras oportunida- 
Quadro 3

Tipologias das Fábricas e Resultados - Lavadoras

\begin{tabular}{|c|c|c|}
\hline Indicador/Fábrica & Brastemp-Rio Claro & Enxuta \\
\hline Estilo e estruturas de gestão & Aberto e participativo & $\begin{array}{l}\text { Fechado, hierárquico - } \\
\text { paternal/mudanças recentes }\end{array}$ \\
\hline Tecnologia, técnicas e layout & Nova, automatizada e integrada & $\begin{array}{l}\text { Mais antiga/menos automatizada/ } \\
\text { não-integrada }\end{array}$ \\
\hline $\begin{array}{l}\text { Local de trabalho e políticas de } \\
\text { recursos humanos }\end{array}$ & $\begin{array}{l}\text { Tarefas novas, benefícios } \\
\text { e oportunidades }\end{array}$ & $\begin{array}{l}\text { Pouca preocupação com a } \\
\text { pressão ou com as condições } \\
\text { de trabalho }\end{array}$ \\
\hline Supervisão & Aberta/menos aberta & Estilo antigo/aberta \\
\hline \multicolumn{3}{|l|}{ RESULTADOS*: } \\
\hline Produtividade & 3,1 & 1,5 \\
\hline Rotatividade & 2,4 \% $1992-12,5 \% 1993$ & $61,2 \%$ \\
\hline Salários & US \$253 & US \$ 292 \\
\hline Supervisão & $1,7 \%$ & $3,8 \%$ \\
\hline $\begin{array}{l}\text { Nível de qualificação: } \\
\text { - \% de qualificados } \\
\text { - \% de semi-qualificados } \\
\text { - \% de não-qualificados }\end{array}$ & $\begin{array}{c}7 \% \\
3 \% \\
90 \%\end{array}$ & $\begin{array}{l}11 \% \\
10 \% \\
79 \%\end{array}$ \\
\hline
\end{tabular}

*Mensuração dos resultados como no Quadro 2.

des de contribuir. Beneficiam-se também de um ambiente muito limpo, organizado e de novas oportunidades de treinamento substanciais. Os trabalhadores da Brastemp-Rio Claro têm ainda uma jornada semanal mais curta e um esquema de carreira, cujo último nível permite-lhes que se tornem técnicos multiqualificados.

Em termos dos resultados, muito são também compatíveis com o modelo otimista (Quadros 2 e 3, linhas 6 a 9). Por exemplo, a produtividade é muito maior na Brastemp-Rio Claro e na Consul III. Além disso, nelas, a rotatividade do trabalho é muito mais baixa, o que sugere a evidência de uma maior estabilidade, a possibilidade de os empregadores cortarem muitos de seus custos de treinamento e de os trabalhadores se sentirem mais satisfeitos por continuarem na empresa. Finalmente, essas estatísticas indicam que a supervisão direta é, de fato, muito menor nas empresas altamente modernizadas.

No entanto, há uma série de advertências a serem feitas a essa imagem. ${ }^{25}$ É possível insinuar que essas empresas não se desenvolveram (e tam- pouco sua dependência) no grau sugerido acima. Por exemplo, greenfields ou uma localização onde o salário é baixo permitiram-lhes oferecer salários abaixo dos padrões da indústria, mas adequados para os mercados de trabalho locais (Quadros 2 e 3, linha 8). Em segundo lugar, essas duas empresas incentivaram critérios amplos de seleção e programas de treinamento que não correspondem muito às habilidades cognitivas para $\mathrm{O}$ desempenho das tarefas. Seus trabalhadores são "treinados" intensivamente e selecionados após serem sistematicamente examinados em relação às atitudes que têm com o empregador e na disputa industrial, "o que é qualidade", a "importância da empresa” etc. São também muito mais jovens do que os das outras empresas (25 anos de idade em comparação a 35) e, talvez, mais maleáveis do ponto de vista da empresa.

$\mathrm{Na}$ Brastemp-Rio Claro, a natureza qualitativa do modelo de utilização do trabalho é mais bem desenvolvida. Por exemplo, seu esquema de carreira considera a qualificação, o treinamento e as atitudes, e os trabalhadores são envolvidos na 
avaliação de suas equipes. É fácil imaginar que isso é difícil para os trabalhadores e os divide, ao mesmo tempo que, para a empresa, fica mais fácil renunciar a algumas de suas funções de supervisão direta anteriores. ${ }^{26}$

Confirmando essa interpretação do maior controle interno tem-se a observação de que, em Joinville, a Consul (e a Whirlpool) fizeram o máximo possível para substituir o sindicato local combativo por um passivo. Toda a produção da Whirlpool brasileira foi progressivamente levada da Brastemp-São Bernardo (uma área-chave de salários altos e militância sindical) para a Brastemp-Rio Claro e para a Consul-Joinville (a primeira uma greenfield e a outra com um sindicato passivo). Não parece ser coincidência que a compra da Consul, da Brastemp (e da Embraco - a principal companhia supridora de componentes) pela Whirlpool tenha permitido ao grupo minimizar os sindicatos, a disputa e os salários dessa maneira.

As atitudes em relação ao trabalho confirmam essas sugestões negativas no que diz respeito à dependência e ao controle do empregador (Pegler, 2000, cap. 5). Por exemplo, os trabalhadores da Consul II sentem-se muito menos monitorados e mais interessados no trabalho do que aqueles que exercem as mesmas funções na Consul III, onde o monitoramento aberto é muito menor e as tarefas são "novas". Por outro lado, os trabalhadores da Brastemp-Rio Claro sentem-se particularmente prejudicados no que diz respeito às pressões do trabalho. Em suma, atitudes em relação ao trabalho não indicam que os trabalhadores das empresas mais altamente modernizadas estejam mais satisfeitos com seu trabalho ou tenham maiores oportunidades de progredir do que os trabalhadores das outras empresas.

Em síntese, essa análise confirmou que há exemplos de modernização abrangente no contexto brasileiro. No entanto, essas empresas parecem desenvolver mecanismos de controle interno e barreiras externas mais fortes, de modo que sua dependência da qualificação e das atitudes de seus trabalhadores seja minimizada e que as ameaças externas sejam contidas ou evitadas. Assim, embora o argumento otimista da modernização mantenha uma certa credibilidade, ele deve se basear em um possível maior grau de lealdade do trabalhador ao empregador. Se isso acontecer, a aparente continuidade das relações industriais adversas, com um baixo grau de confiança, no Brasil, sugere possíveis implicações fundamentalmente negativas sobre as atitudes do trabalhador em relação ao sindicato. A última seção deste artigo retoma essas questões.

\section{O "eixo" de lealdade do trabalhador}

A história das relações de trabalho no Brasil, ao mesmo tempo que freqüentemente paternalista, parece sugerir que os trabalhadores não têm boas razões para confiar muito nos empregadores. A natureza não-representativa de muitos sindicatos durante boa parte do século XX também sugere que a maioria dos trabalhadores confia pouco na vontade ou capacidade dos sindicatos de melhorar sua vida de trabalhador. No entanto, questões genéricas, formuladas aos que fizeram parte da amostra, indicam que a empresa tornou-se uma forte referência para os trabalhadores e que o sindicato continua a ter um interesse mínimo para a maior parte deles (Pegler, 2000, p. 221).

Por exemplo, $52 \%$ da amostra achavam que a empresa tinha muito poder para determinar os meios necessários à sua subsistência ao passo que 38\% mencionaram o Estado. Ao responderem "em quem eles têm mais confiança para a determinação dos meios necessários à sua subsistência", $78 \%$ mencionaram a empresa, outros 16\% citaram inclusive os sindicatos e $6 \%$ referiram-se ao Estado (idem, ibidem). Como esses resultados parecem dar suporte ao argumento otimista da modernização, as duas subseções examinam de maneira mais detalhada essas opiniões aparentemente "positivas em relação ao empregador - negativas em relação aos sindicatos".

\section{O empregador moderno - a natureza da lealdade do trabalhador}

Um grande número de respostas dos trabalhadores incluídos na amostra sugere que o empregador, cuja empresa fosse altamente modernizada, es- 


\section{Quadro 4}

\section{Satisfação com as Políticas do Empregador}

\begin{tabular}{l|l}
\hline Perguntas & Respostas principais \\
\hline $\begin{array}{l}\text { Você é remunerado } \\
\text { adequadamente? }\end{array}$ & $\begin{array}{l}\text { Amostra }=44 \% \text { sim } \\
\text { Resposta positiva mais alta por empresa - Brastemp-Rio Claro (60\%) }\end{array}$ \\
\hline $\begin{array}{l}\text { Seu trabalho é totalmente bem } \\
\text { recompensado? }\end{array}$ & $\begin{array}{l}\text { Amostra }=60 \% \text { sim } \\
\text { Resposta positiva mais alta por empresa - as duas altamente } \\
\text { modernizadas }(76 \% / 83 \% ; \mathrm{p}=0,056)\end{array}$ \\
\hline $\begin{array}{l}\text { A probabilidade de estabilidade } \\
\text { (voluntária) depende de...? }\end{array}$ & $\begin{array}{l}\text { Amostra }=84 \% \text { condições da empresa; } 27 \% \text { condições da } \\
\text { empresa e oportunidades em outras }\end{array}$ \\
& $\begin{array}{l}\text { Trabalhadores das altamente modernizadas - maior ênfase no } \\
\text { desenvolvimento da empresa atual } \\
\text { Trabalhadores das parcialmente modernizadas }- \text { menos ênfase } \\
\text { no desenvolvimento da empresa atual }(\mathrm{p}=0,082)\end{array}$ \\
\hline
\end{tabular}

Fonte: Entrevistas com trabalhadores.

\section{Quadro 5}

Impressões e Expectativas de Ganhos

\begin{tabular}{l|l}
\hline Perguntas & Respostas principais \\
\hline O que você ganhou da empresa? & $\begin{array}{l}\text { Amostra }-47 \% \text { muito, } 53 \% \text { pouco/nada } \\
\text { Qualificados/semi-qualificados mais satisfeitos do que os não-Qualificados } \\
(\mathrm{p}=0,000)\end{array}$ \\
\hline $\begin{array}{l}\text { O que você espera ganhar } \\
\text { da empresa? }\end{array}$ & $\begin{array}{l}\text { Amostra }-35 \% \text { muito, } 21 \% \text { pouco até nada } \\
\text { Qualificados/semi-qualificados têm grande expectativa; não-qualificados } \\
\text { têm baixa expectativa }(\mathrm{p}=0,040)\end{array}$ \\
\hline
\end{tabular}

Fonte: Entrevistas com trabalhadores.

tava apto para conseguir uma força de trabalho interessada muito mais sólida. Por exemplo, ao mesmo tempo que as comparações dos salários regionais também podem estar em jogo, os trabalhadores com baixo salário da Brastemp-Rio Claro são os mais satisfeitos com sua remuneração (Quadro 4, linha 1). De uma maneira mais clara, os trabalhadores das duas empresas altamente modernizadas sentem-se mais confiantes no que diz respeito à compensação (Quadro 4, linha 2). As respostas dos trabalhadores a uma questão sobre o que determina seu desejo de sair ou de ficar (Quadro 4, linha 3) constituem outro indício de que as empresas altamente modernizadas estavam aptas para conseguir uma força de trabalho mais voltada para a empresa.

Todavia, é claro que muitos deles ainda não ganhavam "muito" (Quadro 5, linha 1) e que os grupos mais qualificados tinham uma alta expec- tativa de ganhos futuros (Quadro 5, linha 2). A observação na fábrica e outras respostas confirmam que muitos trabalhadores são céticos em relação ao que ganharam ou vão ganhar nas empresas modernizadas. ${ }^{27}$ A título de exemplo, as oportunidades de participar são altamente voltadas para os problemas (versus benefícios) da empresa, o "treinamento" não os torna mais empregáveis em outras empresas e as expectativas de carreira (na Brastemp-Rio Claro) continuam exatamente como antes. Os trabalhadores da altamente modernizada Consul III não estão de forma alguma satisfeitos com o fato de que trabalhadores menos produtivos da Consul II ganhem os mesmos salários.

Por outro lado, mesmo o nível parcial de modernização nas empresas mais tradicionais levou à opinião generalizada de que a empresa tem mais interesse nos trabalhadores, atualmente, do que no 


\section{Quadro 6 \\ Crença no Interesse da Empresa nos Trabalhadores}

\begin{tabular}{l|l}
\hline Perguntas & Respostas principais \\
\hline $\begin{array}{l}\text { Atualmente, a empresa tem mais? } \\
\text { interesse nos trabalhadores? }\end{array}$ & $\begin{array}{l}\text { Amostra }=70 \% \text { sim } \\
\text { Resposta positiva mais alta por empresa - Brastemp-Rio Claro e Consul II } \\
(76 \%)\end{array}$ \\
\hline $\begin{array}{l}\text { Por que a empresa tem mais } \\
\text { interesse? (lucro ou ênfase } \\
\text { no altruísmo? }\end{array}$ & $\begin{array}{l}\text { Amostra }=67 \% \text { principalmente devido ao lucro } \\
\text { Maior crença no altruísmo por empresa - Brastemp-Rio Claro e Consul II } \\
(\mathrm{p}=0,029)\end{array}$ \\
\hline
\end{tabular}

Fonte: Entrevistas com trabalhadores.

\section{Quadro 7}

\section{Satisfação com Avaliação e Probabilidade de Rotatividade Voluntária}

\begin{tabular}{l|l}
\hline Perguntas & Respostas principais \\
\hline $\begin{array}{l}\text { Você gosta do sistema de avaliação } \\
\text { (promocional)? }\end{array}$ & $\begin{array}{l}\text { Os trabalhadores das duas empresas mais altamente modernizadas } \\
\text { não gostam }(80 \% \text { ou mais }) \\
\text { Trabalhadores de empresas parcialmente modernizadas gostam } \\
(\text { de } 55 \% \text { a } 60 \%)(p=0,012)\end{array}$ \\
\hline $\begin{array}{l}\text { Você espera deixar (voluntariamente) } \\
\text { a empresa nos próximos } 2 \text { anos? }\end{array}$ & $\begin{array}{l}\text { Amostra }-28 \% \text { sim } \\
\text { É muito mais provável que a maior parte dos trabalhadores da Enxuta e da } \\
\text { Brastemp-Rio Claro e } 50 \% \text { dos trabalhadores da Consul III deixem a } \\
\text { empresa }(\mathrm{p}=0,004)\end{array}$ \\
\hline
\end{tabular}

Fonte: Entrevistas com trabalhadores.

passado (Quadro 6, linha 1). Todavia, a maior parte dos trabalhadores (67\%; Quadro 6, linha 2) considerava esse interesse como nitidamente relacionado ao desejo de uma maior lucratividade. O que se observa claramente nessas respostas é que parece que os trabalhadores da Brastemp-Rio Claro têm uma visão mais altruísta das intenções de sua empresa, mas com a qual os trabalhadores da outra empresa altamente modernizada (Consul III) não concordam. Uma vez associada a comentários anteriores sobre atitudes em relação ao trabalho, remuneração e monitoramento (na Consul III), essa constatação sugere que se a hipótese otimista sobre as atitudes em relação ao empregador for confirmada, somente o será em uma das empresas mais modernizadas, a Brastemp-Rio Claro.

No entanto, outros indicadores colocam em dúvida até mesmo esse diferente resultado relativo às atitudes dos trabalhadores na empresa modernizada. Por exemplo, as escalas de preferência indicam que a oportunidade de carreira e a participação eram, juntamente com a remuneração, problemas fundamentais para o trabalhador. ${ }^{28}$ Contudo, nas empresas altamente modernizadas, onde funcionam relações de equipes de trabalho e um esquema de carreira (Brastemp-Rio Claro), os trabalhadores estão muito insatisfeitos com a avaliação (Quadro 7, linha 1).

Embora trabalhem dentro de sistemas de avaliação mais abertos e transparentes, esses trabalhadores ainda consideram que a avaliação é influenciada pela educação e treinamento (versus qualificação) e que, além disso, é subjetiva. Particularmente na Brastemp-Rio Claro, parecem muito insatisfeitos com o fato de que esse processo utilize a pressão dos companheiros. Se considerarmos essa idéia de insatisfação com o empregador em um nível mais geral, é muito significativo que a maioria dos trabalhadores da Brastemp-Rio Claro e muitos da Consul III estejam exatamente com a mesma probabilidade de deixar a empresa voluntariamente que aqueles da muito opressora fábrica Enxuta (Quadro 7, linha 2). 
A chegada recente de outras empresas altamente modernizadas em Rio Claro pode tornar mais pessimistas as atitudes dos trabalhadores da Brastemp-Rio Claro em relação a seu empregador. Isto porque essas novas empresas estão oferecendo salários muito mais altos (baseados na indústria metalúrgica versus mercado de trabalho local) e, conseqüentemente, esse fato também pode modificar a visão positiva do trabalhador da Brastemp-Rio Claro em relação às políticas salariais de seu empregador (Quadro 4).

Os resultados acima, relativos às atitudes em relação ao empregador, colocam em dúvida a proposição de que mesmo o trabalhador brasileiro "passivo" venha a desenvolver uma lealdade ao empregador modernizado. Parece que os pontos de vista dos trabalhadores são muito instrumentais e podem variar de acordo com o que estiver em questão. Em suma, é "como se" aquiescência ou lealdade pudessem ser termos melhor utilizados para se referir às atitudes em relação ao empregador que, neles, está colocando mais e novas expectativas.

Se reconhecermos que os sindicatos podem ter novas e maiores dificuldades de "penetrar" na estrutura dos recursos humanos e das relações industriais que essas empresas estão tentando construir, isso significa que os trabalhadores têm uma demanda latente de uma maior representação do sindicato? Se a resposta for afirmativa, que forma tem essa demanda? A subseção seguinte resume as atitudes dos trabalhadores das amostras em relação aos sindicatos, tanto atualmente quanto no que se refere ao futuro.

\section{Sindicatos como uma "voz" - pontos de vista dos trabalhadores $\mathrm{e}$ expectativas}

Como fica claro com base no Quadro 8, há uma grande variedade no grau de sindicalização entre as empresas pesquisadas. ${ }^{29} \mathrm{O}$ alto nível de sindicalização na Brastemp-São Bernardo reflete o poderoso e influente papel daquele sindicato, tanto nos locais de trabalho quanto de maneira mais geral. As disputas internas e a falta de uma clareza sobre o papel do local de trabalho deixou a sindicalização na Enxuta em níveis muito baixos. Por outro lado, o sindicalismo é muito baixo na altamente modernizada, greenfields, Brastemp-Rio Claro.

O mais surpreendente é que a sindicalização é alta nas duas fábricas da Consul. Ao mesmo tempo que isso pode parecer conflitante com uma interpretação pessimista do processo de modernização, pode ser explicado por duas observações. Em primeiro lugar, como aludido anteriormente, dois meses depois de um grupo radical ter ganho o controle do sindicato local (o dos Mecânicos) em 1989, a empresa o substituiu com êxito por um sindicato (de serviços, não voltado para o local de trabalho), o Sinditherme, muito passivo. Além disso, ao mesmo tempo que as duas empresas têm índices altos de sindicalização, parece que a ligação com o sindicato ativo é o que distingue as fábricas e a seleção de trabalhadores para a fábrica Consul III (Quadro 8, linha 2).

No entanto, as estatísticas de sindicalização podem simplesmente nos dizer muito sobre as atitudes dos trabalhadores. Os pontos de vista de todos aqueles que fizeram parte da amostra podem

\section{Quadro 8}

A Natureza do Sindicalismo, por Amostra e Empresa ${ }^{30}$

\begin{tabular}{l|c|c|c}
\hline Tipo de sindicato & Não-membro & Membro passivo & Membro ativo \\
\hline Amostra & $53 \%$ & $32 \%$ & $15 \%$ \\
\hline POR EMPRESA & $84 \%$ & $16 \%$ & - \\
Rio Claro & $70 \%$ & $30 \%$ & - \\
Enxuta & $12 \%$ & $56 \%$ & $32 \%$ \\
São Bernardo & $47 \%$ & $23 \%$ & $30 \%$ \\
Consul II & $50 \%$ & $33 \%$ & $17 \%$ \\
Consul III & $48 \%$ & $26 \%$ & $26 \%$ \\
Consul Total & & & \\
\hline
\end{tabular}

Fonte: Dados obtidos nas entrevistas. 
Quadro 9

Conhecimento da Política Sindical e Opinião Geral sobre o Sindicato

\begin{tabular}{|c|c|}
\hline Perguntas & Respostas principais \\
\hline $\begin{array}{l}\text { Você está ciente das políticas } \\
\text { do sindicato? }\end{array}$ & $\begin{array}{l}\text { Amostra }-80 \% \text { sim } \\
\text { Por empresa - quanto mais modernizada menor o conhecimento } \\
(\mathrm{p}=0,001)\end{array}$ \\
\hline O sindicato local é bom? & $\begin{array}{l}\text { Amostra - } 71 \text { \% não é bom } \\
\text { Altamente modernizadas - mais negativos }(\mathrm{p}=0,000) \\
\text { Consul II - } 50 \% \text { sim; } 50 \% \text { não } \\
\text { Consul III - } 100 \% \text { não Fonte: Entrevistas com trabalhadores. }\end{array}$ \\
\hline
\end{tabular}

Fonte: Entrevistas com trabalhadores.

\section{Quadro 10}

\section{Impressões do Sindicato com Base em sua Abordagem Política}

\begin{tabular}{l|l}
\hline Perguntas & Respostas principais \\
\hline $\begin{array}{l}\text { As políticas dos sindicatos locais } \\
\text { são .../o sindicato é bom? }\end{array}$ & $\begin{array}{l}\text { Amostra - é mais provável que o sindicato seja julgado bom quando } \\
\text { se considera que ele tem políticas voltadas para o local de trabalho } \\
\text { e para o processo de trabalho }(\mathrm{p}=0,000)\end{array}$ \\
\hline $\begin{array}{l}\text { As políticas dos sindicatos locais são .../. } \\
\text { as políticas dos sindicatos são boas? }\end{array}$ & $\begin{array}{l}\text { Amostra - é mais provável que as políticas do sindicato sejam consideradas } \\
\text { indefinidamente boas quando se considera que ele tem políticas voltadas } \\
\text { para o processo de trabalho }(\mathrm{p}=0,000) .\end{array}$ \\
\hline
\end{tabular}

Fonte: Entrevistas com trabalhadores - tabulação cruzada das respostas.

ser usados para testar mais especificamente as relações sugeridas entre a modernização e as atitudes referentes ao sindicato e ao sindicalismo. A discussão, a seguir, dos indicadores de atitudes confirma a visão de que o contexto e a estratégia do sindicato terão um forte impacto sobre a capacidade da modernização moldar as atitudes dos trabalhadores como a teoria sugere.

Em primeiro lugar, como sintetiza o Quadro 9, quanto mais modernizada a empresa, menos conhecimento das políticas sindicais têm os trabalhadores (linha 1). Uma grande proporção da amostra (71\%), particularmente das empresas altamente modernizadas, achava também que o sindicato não era bom (linha 2). Uma questão semelhante sobre as atitudes em relação às políticas sindicais confirma essa opinião (Pegler, 2000, pp. 243-244). Portanto, parece que essas empresas conseguiram (por meio de persuasão e/ou seleção) uma força de trabalho menos voltada para o sindicato.
Todavia, o resultado nas fábricas da Consul é ambíguo (Quadro 9, linha 2). Esta e outras respostas (vide abaixo) sugerem que os trabalhadores da amostra supostamente passiva da Consul III podem ser mais negativos em relação a seu sindicato (passivo), o Sinditherme, do que seus análogos da Consul II. Muito pelo contrário; além do mais, talvez muitos trabalhadores da Consul II ainda pensem em termos de seu sindicato mais velho e mais ativo, o dos Mecânicos.

No entanto, o conhecimento dos trabalhadores sobre as orientações muito diferentes de seus sindicatos foi nitidamente refletido em seus pontos de vista a respeito de como percebiam as políticas dos mesmos - 30\% afirmaram nada perceber, 19\% referiram-se aos problemas nos locais de trabalho e 51\% consideraram que a orientação era tradicional (salário e serviço) (Pegler, 2000). Além disso, a tabulação cruzada das respostas de toda a amostra indica que a probabilidade de ser consi- 


\section{Quadro 11}

\section{Expectativas em Relação às Políticas do Sindicato}

\begin{tabular}{l|l}
\hline Perguntas & Respostas principais \\
\hline Que políticas o sindicato & Amostra - 65\% responderam: voltadas para problemas no local de trabalho/ \\
deveria ter? & sno processo de trabalho; 23\% para problemas tradicionais; $12 \%$ "nada" \\
& Por empresa: \\
& Brastemp-Rio Claro - um número significativo disse "nada" (33\%; $\mathrm{p}=0,012)$ \\
& Consul III - 100\% disseram: problemas no local de trabalho/no processo \\
& de trabalho \\
& Consul II - 70\% disseram: problemas no local de trabalho/no processo de \\
& trabalho; $30 \%$ tradicionais \\
\hline
\end{tabular}

Fonte: Entrevistas com trabalhadores.

Quadro 12

Impressões de como as Políticas dos Sindicatos São e Deveriam Ser

\begin{tabular}{l|ll}
\hline Pergunta/Resposta & $\begin{array}{l}\text { As políticas dos sindicatos } \\
\text { deveriam ser baseadas } \\
\text { no local de trabalho }\end{array}$ & $\begin{array}{l}\text { O sindicato deveria ter } \\
\text { apenas políticas tradicionais }\end{array}$ \\
\hline $\begin{array}{l}\text { As políticas dos sindicatos enfocam } \\
\text { o local de trabalho }\end{array}$ & $17 \%$ dos que responderam & $6 \%$ dos que responderam \\
\hline $\begin{array}{l}\text { As políticas dos sindicatos enfocam } \\
\text { apenas os problemas tradicionais }\end{array}$ & $48 \%$ dos que responderam & $16,5 \%$ dos que responderam \\
\hline
\end{tabular}

Fonte: Tabulação cruzada das respostas.

derado bom (Quadro 10) seria maior se o sindicato tivesse políticas ativas no local de trabalho.

Neste sentido, o que então o sindicato deveria fazer para obter maior apoio dos trabalhadores (sejam ou não, no presente, filiados a ele)? Neste caso, no que diz respeito a toda a amostra, parece que muitos trabalhadores acreditam que o sindicato deveria fazer mais. Mais de $60 \%$ dos trabalhadores da amostra achavam que seu sindicato deveria estar envolvido com os problemas do local de trabalho (Quadro 11). Cerca da metade da amostra também achava que o sindicato ainda não tinha, mas deveria ter, políticas claras que enfocassem o local de trabalho (Quadro 12, linha 2).

Ao mesmo tempo que o ponto de vista de todos os trabalhadores da Consul confirma uma insatisfação com as políticas sindicais, parece que os trabalhadores da Consul III estão particularmente insatisfeitos com a falta de uma abordagem (crítica) do local de trabalho por seu sindicato passivo (Quadro 11). Por outro lado, os trabalhadores da Consul II consideram que seu sindicato deveria fazer mais, tanto em relação aos problemas tradicionais quanto aos do local de trabalho (Quadro 11). Na verdade, um ponto de vista totalmente típico dos trabalhadores da Consul foi confirmado pelo seguinte sentimento: "sindicato?... nós não temos um sindicato aqui. Se você se queixa ao sindicato, aqui, você é colocado na rua no dia seguinte!". ${ }^{31}$

Mais surpreendente é o fato de os trabalhadores das greenfields (Brastemp-Rio Claro) não estarem satisfeitos com seu sindicato local (Quadros 9 e 11), embora não sejam desfavoráveis aos sindicatos em geral. Muitos consideravam que "sindicatos são importantes... protegem os trabalhadores... mas não aqui, não são necessários aqui”32. Assim, em comparação a outras empresas, parece que a administração na Brastemp-Rio Claro teve mais êxito em conseguir uma força de tra- 
Quadro 13

Avaliação do Sindicato em Relação à Greve

\begin{tabular}{l|l}
\hline Perguntas & Respostas principais \\
\hline Quando um sindicato deve & 1. Amostra - $45 \%$ nunca, 31\% por salários mais altos, 24\% acerca de \\
considerar uma greve? & qualquer questão em disputa \\
& 2. Trabalhadores das duas empresas mais tradicionais - maioria sem \\
& restrições $(\mathrm{p}=0,019)$ \\
& 3. Trabalhadores da Consul III altamente modernizada, precisamente \\
& divididos em relação aos três pontos de vista e mais favoráveis à greve do \\
& que os trabalhadores da Consul II (65\% dos quais disseram nunca) \\
\hline O sindicato é bom/quando deve & Amostra - para 37\% o sindicato não é bom e deveria considerar \\
considerar a possibilidade de greve? & a possibilidade de greve \\
\hline
\end{tabular}

Fonte: Entrevistas com trabalhadores.

balho que, apesar de freqüentemente acreditar nos sindicatos em geral, tinha poucas ligações com seu sindicato local. Todos os outros trabalhadores da amostra nitidamente queriam um sindicato local com uma abordagem ativa e que questionasse a mudança no local de trabalho.

Essa idéia dos desejos latentes, por parte dos trabalhadores, de um sindicato mais ativo e independente tem o suporte de outras respostas. Por exemplo, $55 \%$ da amostra consideraram que o sindicato deveria fazer greve, seja por algum problema específico ou por uma série ilimitada de questões (Quadro 13, linha 1). Confirmando também a idéia de que alguns trabalhadores das empresas altamente modernizadas não estão satisfeitos com o sindicalismo passivo, os trabalhadores da Consul III registraram uma atitude positiva mais militante e de greve do que seus colegas de trabalho da Consul II (Quadro 13, linha 1). Além disso, o fato de que $55 \%$ da amostra considerassem alguma necessidade de greve, mas somente $47 \%$ fossem sindicalizados (Quadro 8) dá um peso maior a esses desejos latentes. Por sua vez, esse peso dá mais suporte ao fato de que $37 \%$ da amostra achassem que o sindicato não era bom e que algum tipo de greve deveria ser realizada (Quadro 13, linha 2).

Em suma, a gerência na ultra moderna Brastemp-Rio Claro conseguiu uma força de trabalho que, embora fosse favorável aos sindicatos em geral, não considerava que necessitasse de um sindicato naquele local. Todavia, essa reticência as- sociada ao sindicato dá motivo para sugerir que a emergência da lealdade ao empregador continua em questão. Fora das situações de greenfields, parece que se um sindicato for independente e estiver ativamente envolvido com as questões do local de trabalho não perderá o apoio do trabalhador. As respostas dos trabalhadores nas empresas (tanto tradicionais quanto em outras altamente modernizadas) sugere que existe até uma chance de que os trabalhadores aumentem seus vínculos e apóiem um sindicato desse tipo.

\section{Resumo e conclusão}

A análise das evidências deste estudo permite que seja feito um grande número de reflexões sobre as questões da dependência do empregador e da lealdade do trabalhador no contexto brasileiro. Em primeiro lugar, ao mesmo tempo que há um número crescente de exemplos da ampla modernização no Brasil, este estudo sugere que empresas como essas reagirão com uma série de políticas à perspectiva de se tornarem mais dependentes da qualificação e das atitudes dos trabalhadores. Novas formas de controle do trabalhador têm sido, por elas, desenvolvidas ou refinadas. As greenfields podem ajudar muito nesse processo. No que diz respeito à influência sindical, políticas tradicionais para evitar ou minimizar os sindicatos têm sido complementadas pela mensagem - "Por que são necessários quando as condições dentro 
da 'família da empresa' são boas?”. A aplicação desse modelo de recursos humanos (HRM) unitarista no contexto das relações industriais brasileiras atuais torna bastante improvável que a dupla lealdade tanto ao empregador quanto ao sindicato seja muito significativa.

Em segundo lugar, apesar desse cenário pessimista, a evidência sugere que os trabalhadores podem ser persuadidos a pensar em uma negociação que inclua outras questões além da remuneração. Muitos deles são também, em princípio, favoráveis a essa idéia e, conseqüentemente, aqueles das empresas mais modernizadas têm uma abordagem mais baseada na empresa. Todavia, como acontece com uma série de atitudes dos trabalhadores relacionadas a muitos novos aspectos de seu trabalho, o grau de ligação com a empresa é limitado. A maioria dos trabalhadores está insatisfeita no que diz respeito às suas relações com a empresa (por exemplo, o sistema de avaliação), enquanto muitos continuam a esperar ganhos "futuros". Devido a essas incertezas, a probabilidade de que os trabalhadores das empresas mais modernizadas permaneçam voluntariamente em seu emprego atual não é maior do que a dos trabalhadores das empresas mais tradicionais.

Em terceiro lugar, no que diz respeito à relação entre o trabalhador e o sindicato, o cinismo dos trabalhadores para com o sindicato pode ter sido intensificado pelas políticas da empresa altamente modernizada. O "eleitorado" dos sindicatos continua muito cético e pode até ter modificado suas prioridades. No entanto, parte desse resultado pode ser conseqüência muito mais das políticas anti-sindicais, exercidas pelas empresas, do que do efeito persuasivo das políticas internas por si só. Além disso, apesar dos baixos níveis de participação nos sindicatos (ou de sindicalismo ativo) nas empresas mais modernizadas, muitos trabalhadores são claramente favoráveis ao sindicalismo e às greves. Todavia, nesses casos, o apoio ao sindicato local depende de suas políticas serem voltadas para a promoção dos principais interesses dos trabalhadores relativos ao local de trabalho.

Em quarto lugar, embora os resultados específicos aqui apresentados sejam influenciados pelo contexto brasileiro, levantam questões sobre os fundamentos atitudinais e comportamentais da modernização em qualquer contexto. As necessidades dos trabalhadores parecem ser muito práticas e instrumentais e sua "lealdade" pode mudar de acordo com a questão e ao longo do tempo. Enquanto os empregadores atuam para minimizar o risco de se tornarem mais dependentes dos trabalhadores, o comportamento dos últimos, quando muito, parece indicar apenas que eles têm mais lealdade a seu empregador. Além disso, fora das greenfields mais isoladas, os interesses latentes de muitos trabalhadores indicam que os sindicatos não deverão se tornar mais ineficazes e irrelevantes - se habilmente desenvolverem novas e ativas estratégias para os trabalhadores no local de trabalho.

Finalmente, em um nível mais conceitual, esses resultados fornecem muito mais suporte para uma perspectiva de processo de trabalho do que para as hipóteses otimistas. Um tipo de abordagem como a de Burawoy (1985) - particularmente uma vez que novas e mais sutis formas de controle são levadas em conta - parece mais apropriada. Dentro dessa perspectiva, intermediação e contexto (inclusive o papel das companhias transnacionais, das estratégias dos sindicatos e das normas de relações industriais) podem desempenhar um importante papel na determinação da forma e dos efeitos da modernização.

\section{NOTAS}

1 Entre os trabalhos mais conhecidos estão o de J. Womack et al., 1990, e o de N. Oliver e B. Wilkinson, 1988/1992.

2 Como discutido na seção 2 deste artigo.

3 Os autores que seguem essa linha, citados neste artigo, são: Lincoln e A. Kallenberg, 1989; T. Kochan e P. Osterman, 1994; e E. Applebaum e R. Batt, 1994.

4 Ver, particularmente, o resumo dos elementos do modelo compilado em Kochan e Osterman, 1994, p. 45-58.

5 Ver nota 3. Todavia, os autores clássicos sobre esses temas foram evidentemente M. Piore e C. Sabel, 1984. 
6 Questão sucintamente colocada em Lincoln e Kallenberg, 1989, p. 4.

7 Outro importante protagonista desse tema é M. Piore, 1994, p. 512-544.

8 Questão mencionada pela literatura geral em Lincoln e Kallenberg, 1989, pp. 4 e 25 e capítulo 9. Na verdade, as análises internacionais anteriores observam que a satisfação com o emprego está fortemente relacionada à redução da rotatividade e ao absenteísmo, e não à lealdade para com a empresa ou ao desempenho. Ver D. Guest, 1987, p. 513-514; e D. Guest e P. Dewe, 1991.

9 Analisado em Pegler, 2000, p. 17-18.

10 Idem, p. 18-20.

11 Isso parece corresponder à terceira e mais sutil forma de poder (controle) sugerida por S. Lukes, 1977.

12 Para uma excelente discussão dessas questões e dos novos problemas criados pela modernização das fábricas, ver P. Ackers et al. (eds.), 1996.

13 Para uma boa discussão sobre as opções de identidade dos sindicatos, ver também R. Hyman, 1994. O papel crítico do contexto para as opções do sindicato e para o debate sobre a lealdade é bem discutido em S. Deery et al., 1994, p. 581-597.

14 Por exemplo, em 1990, o governo federal lançou um programa de assistência para qualidade e produtividade na indústria, seguindo as linhas sugeridas pela teoria otimista (Ministério da Justiça et al., 1990). Um dos estudos brasileiros mais otimistas é o de J. Gonçalves e C. Dreyfus (orgs.), 1995.

15 Para um trabalho clássico sobre o assunto, ver G. Gomes, 1986.

16 As características desse modelo não são questionadas na literatura. Ver, por exemplo, K. Erikson, 1977 e M. Alves, 1989, p. 39-45.

17 Ver, por exemplo, em relação ao período militar, M. Alves, 1989, p. 47-49.

18 Essas questões são discutidas com acuidade em J. Morais, 1992, p. 58-59.

19 Um estudo clássico sobre as condições dos locais de trabalho até esse período é o de J. Humphrey, 1982.
20 Para uma análise desses estudos, ver Y. Cohen, 1989, cap. 1, e para seu estudo ver caps. 3-5. Todavia, esse tipo de modelo de sindicato mudou significativamente com a emergência dos "novos" movimentos sindicais, mais representativos e com o foco nas fábricas, a partir do final da década de 1970 (M. E. Keck, 1989).

21 Termo cunhado por A. Fleury, 1982; ver também Humphrey, 1982.

22 Conforme sugerido por J. Humphrey, 1993a, p. 255-256.

23 Uma apresentação detalhada dessas observações pode ser encontrada em Pegler, 2000, cap. 4.

24 Idem, ibidem.

25 Idem, ibidem.

26 Mesmo um maior apoio ao grau de prerrogativa gerencial envolvido também pode ser visto a partir do fato de que a empresa foi facilmente capaz de suspender o esquema de carreira (devido às suas preocupações com o aumento de salários) em 1998, e o reinstitui em 2001.

27 Para uma discussão completa ver Pegler, 2000, p. 201-211.

28 Idem, p. 180-184.

29 Esses números estão relacionados aos adicionais dos membros voluntários dos sindicatos e não ao imposto sindical compulsório, que é descontado do salário de todos os trabalhadores para sustentar as estruturas sindicais.

30 Os sindicalismos ativo e passivo se auto definem. Passivo refere-se somente ao uso dos serviços do sindicato, enquanto ativo se refere a outras relações, mais políticas, com o sindicato.

31 Entrevista com trabalhador da Consul, CONII14 em Pegler, 2000, p. 256.

32 Entrevista com trabalhador da Brastemp-Rio Claro, RCL 18, idem, p. 255.

\section{BIBLIOGRAFIA}

ABRAMO, L. (1988), "A subjectividade do trabalhador frente à automação", in R. T. Ne- 
der et al., Automação e movimento sindical no Brasil, São Paulo, Hucitec.

ACKERS, P., SMITH, C. \& SMITH, P. (eds.) (1996), The new workplace and trade unionism. Londres/Nova York, Routledge.

ALVES, M. (1989), "Trade unions in Brazil: a search for autonomy and organisation"; in E. Epstein (ed.), Labour autonomy and the State in Latin America. Boston, Unwin Hyman.

APPELBAUM, E. \& BATT, R. (1994), The New American Workplace: transforming work systems in the United States. Nova York, ILR Press.

BEMMELS, B. (1995), "Dual commitment: unique construct or epiphenomenon?". Journal of Labour Research, 16 (4).

BLYTON, P. \& TURNBUlL, P. (eds.) (1996), Reassessing buman resource management. Londres, Sage.

BOITO, A. (1994), "The State and trade unionism in Brazil". Latin American Perspectives, 21 (1).

BORDIN, M. (1986), "The Brazilian industrial relations system (1930-1964): unionism or corporatism?". Labour and Society, 11 (1).

BRESIANI, L. \& ODA, N. (1995), "Inovação tecnológica, mudança organizacional e negociação coletiva: o panorama brasileiro e o caso do complexo automotivo no ABC". Caderno Técnico - Reestruturação Produtiva no Brasil, São Paulo, 22, CNI/SESI.

BURAWOY, M. (1985), The politics of production. Londres, Verso.

CARVALHO, R. (1995), "Coping with change in the economy: new technologies, organisational innovation and economies of scale and scope in the Brazilian engineering industry". Texto para Discussão, Brasilia, IPEA.

CARVAlHO, R. \& SCHMITZ, H. (1989), "Fordism is alive and well in Brazil". Institute of Development Studies Bulletin, 20 (4).
CASTRO, N. (1993), "Modernização e trabalho no complexo automotivo brasileiro: reestruturação industrial ou japanização de ocasião?". Novos Estudos CEBRAP, 37.

COHEN, Y. (1989), The manipulation of consent: the State and working class conciousness in Bra$z i l$. Pittsburgh, Pittsburgh University Press.

CORDOVA, E. (1989), "From corporatism to liberalisation: the new directions of the Brazilian system of industrial relations". $\mathbf{L a}$ bour and Society, 14 (3).

COUTINHO, L. (1992), "A Terceira Revolução industrial e tecnológica". Economia e Sociedade, 1 , ago.

DAVIS, C. \& COLEMAN, K. (1986), "Labour and the State: union incorporation and working class politicisation in Latin America". Comparative Political Studies, 18 (4).

DAWSON, P. \& WEBB, J. (1989), "New production arrangements: the totally flexible cage? Work, Employment and Society, 3 (2).

DEDOUSSIS, V. (1995), "Simply a question of cultural barriers?: the search for new perspectives in the transfer of management practices". Journal of Management Studies - Special Issue, 32 (6).

DEERY, S., IVERSON, R. \& ERWIN, P. (1994), "Predicting organisational and union commitment: the effect of industrial relations climate". British Journal of Industrial Relations, 32 (4).

DELBRIDGE, R. (1995), "Surviving JIT: control and resistance in a Japanese transplant". Journal of Management Studies - Special Issue, 32 (6).

DELBRIDGE, R., TURNBULL, P. \& WILKINSON, B. (1992), "Pushing back the frontiers: management control and work intensification under JIT/TQM factory regimes". New Technology, Work and Employment, 7 (2).

DIEESE. (1995), "Política industrial, restruturação produtiva e organização do trabalho". Indicadores e Informaçôes Relevantes, 1 (5). 
ELGAR, T. \& SMITH, C. (eds.) (1994), Global japanization?: the transnational transformation of the labour process. Londres/Nova York, Routledge.

ERICKSON, K. (1977), The Brazilian corporate State and working class politics. Berkeley, University of California Press.

FERRAZ, J. et al. (1992), Development technology and flexibility: Brazil faces the industrial divide. Londres/Nova York, Routledge.

FLEURY, A. (1991), "Flexible automation in Brazil", in S. Watanabe (ed.), Microelectronics in 3rd world countries: quality, competition, international development of labour and employment, Geneva, ILO.

(1983), "Rotinização do trabalho: o caso das indústrias mecânicas", in A. Fleury \& N. Vargas (eds.), Organização do trabalho, $\mathrm{S}_{\text {,O Paulo, Atlas. }}$

FLEURY, A. \& HUMPHREY, J. (1993), "Human resources and the diffusion and adaptation of new quality methods in Brazil". IDS Research Report, 24.

GARRAHAN, P. \& STEWART, P. (1992), "Work organisations in transition: the human resource management implications of the "Nissan Way". Human Resource Management Journal, 2 (2).

GAUDIER, M. (1988), "Workers" participation within the new industrial order: a review of literature". Labour and Society, 13 (2).

GOMES, G. (1986), The roots of State intervention in the Brazilian economy. Nova York/Londres, Praeger.

GONÇALVES, J. \& DREYFUS, C. (orgs.) (1995), Reengenharia das empresas: passando a limpo. São Paulo, Atlas.

GRAHAM, L. (1994), "How does the Japanese Model transfer to the United States?: A view from the line", in T. Elgar \& C. Smith (eds.), Global japanization?: the transnational transformation of the labour process, Londres, Routledge.
GUEST, D. (1995), "Human resource management, trade unions and industrial relations", in J. Storey (ed.), Human resource management: a critical text, Londres, Routledge.

(1987), "Human resource management and industrial relations". Journal of $\mathrm{Ma}$ nagement Studies, 24 (5).

GUEST, D., PECCEI, R. \& THOMAS, A. (1993), "The impact of employee involvement on organisational commitment and "us and them" attitudes. Industrial Relations Journal, 24 (3).

GUEST, D. \& DEWE, P. (1991), "Company or trade union: which wins worker allegiance?". British Journal of Industrial Relations, 29 (1).

(1988), "Why do workers belong to a trade union?". British Journal of Industrial Relations, 26 (2).

HARRISON, G. (1986), "Trade unions and labour management: a Brazilian case study". PhD Thesis, Department of Sociology, University of Manchester.

HIRATA, H. (org.) (1993), Sobre o "modelo" japonês: automatização, novos formas de organização e de relações de trabalho. São Paulo, Edusp/Aliança Cultural Brasil-Japão.

HUMPHREY, J. (1995), "The adoption of Japanese management techniques in Brazilian industry". Journal of Management Studies Special Issue, 32 (6).

(1994), "Japanese" production methods and the changing position of direct production workers: evidence from Brazil", in T. Elgar \& C. Smith (eds.), Global japanization: the transnational transformation of the labour process, Londres, Routledge.

(1993 ), "Japanese production management and labour relations in Brazil". Journal of Development Studies, 30 (1).

(1993a), "Adaptando o "modelo japonês" ao Brasil", in H. Hirata (org.), Sobre o modelo japonês, São Paulo. 
(1982), Capitalist control and workers' struggle in the Brazilian auto industry. Princeton, Princeton University Press.

HYMAN, R. (1994), "Changing trade union identities and strategies", in R. Hyman \& A. Ferner (eds.), New frontiers in European industrial relations.

JERMIER, J., KNIGHTS, D. \& NORN, W. (eds.) (1993), Resistance and power in organisations. Londres, Routledge.

KECK, M. E. (1989), "The new unionism in the Brazilian transition"; in A. Stepan (ed.), Democratising Brazil: problems of transition and consolidation, Nova York, Oxford University Press.

KELLY, J. \& KELLY, C. (1991), "Them and Us: social psychology and the "new industrial relations". Journal of Industrial Relations, 29 (1).

KENNEY, M. \& FLORIDA, R. (1995), "The transfer of Japanese management styles in two US transplant industries: autos and electronics". Journal of Management Studies Special Issue, 32 (6).

KESLER, G. (1995), "A model \& process for redesigning the HRM role, competencies and work in a Major multinational corporation". Human Resource Management, 34 (2).

KISSLER, L. (1992), "Modernização industrial através da participação dos trabalhadores?". Trabalho apresentado no seminário "Novas Formas de Gestão para a Qualidade e Produtividade", Brasília, IPEA.

KNIGHTS, D. \& WILLMOTT, H. (eds.) (1993), Making quality critical: new perspectives on the labour process. Londres, Routledge.

(1986), Managing the labour process. Aldershot, Gower.

KOCHAN, T. \& OSTERMAN, P. (1994), The mutual gains enterprise. Boston, Harvard Business School Press.
LEITE, M. (1994a), O futuro do trabalbo: novas tecnologias e subjectividade operária. São Paulo, Página Aberta.

(1994b), "Reestruturação produtiva, novas tecnologias e novas formas de gestão da mão-de-obra", in J. Mattoso et al. (orgs.), O mundo do trabalbo: crise e mudança no final do século, São Paulo, Scritta.

LIEDKE, E. (1991), "Inovação tecnológica e ação sindical nas indústrias metal-mecânica e eletro-electrônica no Rio Grande do Sul”. Trabalho apresentado no seminário latino-americano "Modernização Tecnológica e Trabalho: Perspectivas para o setor Metalúrgico", São Paulo, LABOR/FE-Unicamp.

LIMA, I. (1989), Análise das conseqüências da utilização das filosofias e técnicas japonesas da gestão da produção e o rendimento das empressas. Dissertação de mestrado. Universidade Federal do Rio Grande do Sul.

LINCOLN, J. \& KALENBERG, A. (1989), Culture, control and commitment: a study of work organisation and work attitudes in the US and Japan. Cambridge, Cambridge University Press.

LOPES, J. R. B. (1964), Sociedade indústrial no Brasil. São Paulo, Difusão Européia do Livro.

LUKES, S. (1977), Power: a radical view. 3 ed., Londres, Macmillan.

MANGABEIRA, W. (1991), Union politics and workplace militancy: a case study of Brazilian steelworkers in the 1980's. $\mathrm{PhD}$ Thesis. London School of Economics, University of London.

MATTOSO, J., NETO, J., OLIVEIRA, C., OLIVEIRA, J. \& POCHMANN, M. (orgs.) (1994), O mundo do trabalho: crise e mudança no final do século, São Paulo, Scritta/Página Aberta. 
MERICLE, K. (1977), "Corporativism control of the working class: authoritarian Brazil since 1964", in J. Maloy (ed.), Authoritarianism and corporatism in Latin America, Pittsburgh, University of Pittsburgh Press.

MINISTÉRIO da Justiça et al. (1990), Programa brasileiro da qualidade e produtividade, Brasília.

MOISÉS (1982), "What is the strategy of the new syndicalism?". Latin American Perspectives, Issue $35(9,4)$.

MORAIS, J. (1992), 'New unionism' and union politics in Pernambuco (Brazil) in the 1980's. PhD Thesis, LSE, University of London.

MORRIS, J. \& WILKINSON, B. (eds.) (1995), "The transfer of Japanese management to Alien Institutional Environments". Journal of Management Studies - Special Issue, 32 (6).

NORRIS, J. \& MUNDAY, M. (1995), "The Iron Fist in the Velvet Glove: management and organisation in Japanese manufacturing transplants in Wales". Journal of Management Studies - Special Issue, 32 (6).

OLIVER, N. \& WILKINSON, B. (1988/1992), The japanization of British industry. Oxford, Basil Blackwell.

PAYNE, L. (1993), Brazilian industrialists and democratic change. Baltimore, Johns Hopkins University Press.

PEGLER, L. (2000), Workers, unions and the "politics of modernisation": labour process change in the Brazilian white goods industry, $\mathrm{PhD}$ Thesis, LSE, University of London.

PIORE, M. (1994), "Unions: a reorientation to survive", in C. Kerr \& P. Staudohar (eds.), Labor economics and industrial relations, Londres.

PIORE, M. \& SABEL, C. (1984), The second industrial divide: possibilities for prosperity. Nova York, Basis Books.
RANIS, P. (1991), "View from below: working class consciousness in Argentina". Latin American Research Review, 26 (2).

REINHART, J., ROBERTSON, D., HUXLEY, C. \& WAREHAM, J. (1994), "Reunifying conception and execution of work under Japanese production management: a Canadian case study", in T. Elgar \& C. Smith (eds.), Global japanization?: the transnational transformation of the labour process, Londres, Routledge.

RODRIQUES, L. M. (1970), Industrialização e atitudes operárias: Estudo de um grupo de trabalhadores, São Paulo, Brasiliense.

SALERNO, M. (1993), "Modelo japonês, trabalho brasileiro", in H. Hirata (org.), Sobre o modelo japonês, São Paulo: Edusp/Aliança Cultural Brasil-Japão.

SALM, C. \& FOGAÇA, A. (1992), "Modernização industrial e a questão dos recursos humanos". Economia e Sociedade, 1, ago.

SEWELL, G. \& WILKINSON, B. (1992), "Someone to watch over me: surveillance, discipline and the just-in-time labour process", Sociology, 26 (2).

SILVA, E. B. (1991), Refazendo a fábrica fordista. São Paulo, Hucitec.

SPENCER, A. (1994), "Models of organisation and Total Quality Management: a comparison and critical evaluation". Academy of $\mathrm{Ma}$ nagement Review, 19 (3).

STOREY, J. (ed.) (1995), Human resource management: a critical text. Londres/Nova York, Routledge.

STURDY, A., KNIGHTS, D. \& WILLMOTT, H. (eds.) (1992), Skill and consent: contemporary studies in the labour process, Londres, Routledge.

TAYLOR, B., ELGAR, T. \& FAIRBROTHER, P. (1994), "Transplants and emulators: the fate of the Japanese model in British electronics", in T. Elgar \& C. Smith (eds.), Global japanization?: the transnational 
transformation of the labour process, Londres, Routledge.

TUCKMAN, A. (1994), "The yellow brick road: total quality management and the restructuring of organisational culture". Organisational Studies, 15 (5).

VARGAS, N. (1985), "Gênese e difusão do taylorismo no Brasil". Revista Ciências Sociais Hoje, São Paulo, Cortez/Anpocs.

WALTON, R. (1985), "From control to commitment in the workplace". Harvard Business Review, mar.-abr.

WIARDA, H. (1978), "Corporative origins of the Iberian and Latin American labour relations systems". Studies in Comparative International Development, 13 (1).

WICKENS, P. (1994), "Lean production and beyond: the system, its critics and the future". Human Resource Management Journal, 3 (4).

WOMACK, J. \& JONES, D. (1994), "From lean production to the Lean Enterprise". Harvard Business Review, mar.-abr.

WOMACK, J., JONES, D. \& ROOS, D. (1990), The machine that changed the world. Nova York, Rawson Macmillan [A máquina que mudou o mundo, Rio de Janeiro, Campus]. 


\section{"DEPENDÊNCIA" DO EMPRE- GADOR E "LEALDADE" DO TRABALHADOR NA FÁBRICA DO FUTURO: EVIDÊNCIA COM BASE NO BRASIL}

Lee Pegler

\section{Palavras-chave}

Modernização; Empregador; Trabalhador; Dependência; Lealdade.

Este artigo aborda o debate a respeito das conseqüências da modernização das fábricas sobre as atitudes do trabalhador em relação ao empregador e ao sindicato. É resultado de um estudo com base em uma pesquisa na indústria brasileira de refrigeradores e de máquinas de lavar durante a década de 1990.

Alguns especialistas sugerem que os empregadores que modernizarem suas fábricas vão se tornar mais dependentes da qualificação e das atitudes de seus empregados. Outros alegam que os trabalhadores das empresas modernizadas serão persuadidos a fazer "mais do que o estabelecido em contrato", devido ao surgimento de uma forma de vínculo forte e direto com o empregador. Além disso, não se sabe que conseqüência isso poderá ter sobre as atitudes dos trabalhadores em relação a seu sindicato.

Embora os resultados sejam influenciados pelo contexto brasileiro, levantam questões sobre os fundamentos atitudinais e comportamentais da modernização em qualquer contexto.

\section{EMPLOYER 'DEPENDENCE' AND WORKER 'ALLEGIANCE' WITHIN THE FACTORY OF THE FUTURE: EVIDENCE FROM BRAZIL}

Lee Pegler

\section{Keywords}

Modernisation; Employer; Worker; Dependence; Allegiance.

This paper presents the debate about factory modernisation effects on worker's attitudes to the employer and the union. It results from a study drawn on a research at Brazilian White Goods industry during the 1990s.

Some commentators have suggested that employers who modernise their factory will become dependent on the skills and attitudes of their employees. Others suggest that workers in modernised firms will be persuaded to go 'beyond contract' due to the emergence of a strong and direct form of attachment to their employer. Moreover, it is uncertain what effect this may have on workers' attitudes to their union. While the results are influenced by the Brazilian context they do raise questions about the attitudinal and behavioural underpinnings of modernisation in any environment.

\section{DÉPENDANCE DE L'EMPLOYEUR ET LOYAUTÉ DU TRAVAILLEUR DANS L'USINE À L'AVENIR: DES ÉVIDENCES BASÉES SUR DES DONNÉES DU BRÉSIL}

Lee Pegler

\section{Mots-clés}

Modernisation; Employeur; Travailleur; Dépendence; Loyauté.

Cet article présente le débat sur les conséquences de la modernisation des usines sur les attitudes du travailleur par rapport à l'employeur et au syndicat. Il est le résultat d'une étude développée à partir d'une recherche, menée pendant les années 1990, auprès de l'industrie brésilienne de réfrigérataires et de machines à laver.

Certains experts suggèrent que les employeurs qui modernisent leurs usines deviendront plus dépendants de la qualification et des attitudes de leurs employés. D'autres suggèrent que les travailleurs des entreprises modernisées seront persuadés à faire "plus de ce qui est établi sur le contrat" en raison de la naissance d'un type de lien fort et direct avec l'employeur. En outre, on ne sait pas quelles en sont les conséquences en ce qui concerne les attitudes des travailleurs par rapport à son syndicat. Même si les résultats sont marqués par le contexte brésilien, ils posent des questions concernant les motivations des attitudes et des comportements devant les effets de la modernisation dans n'importe quel contexte. 